\title{
Quantifying Trace Element Variations in Chrysocolla by Clustering FEG-EPMA Hyperspectral Maps
}

Aaron Torpy ${ }^{1}$, Rong Fan ${ }^{2}$, Nicholas Wilson ${ }^{1}$, Colin MacRae ${ }^{3}$ and Peter Austin ${ }^{2}$

${ }^{1}$ CSIRO Mineral Resources, Clayton, Australia, ${ }^{2}$ CSIRO Mineral Resources, Australia, ${ }^{3}$ CSIRO Mineral Resources, Clayton, Victoria, Australia

Chrysocolla is an abundant hydrated copper silicate secondary mineral with a nominal formula of $\mathrm{Cu}_{2}{ }_{-x} \mathrm{Al}_{x}\left(\mathrm{H}_{2}-\mathrm{Si}_{2} \mathrm{O}_{5}\right)(\mathrm{OH})_{4} \cdot n \mathrm{H}_{2} \mathrm{O}(x<1, \mathrm{n} \sim 0.25)$. Chrysocolla is valued as a semi-precious stone with a vivid blue-green colour, and has been used in jewellery and ornaments since antiquity. Structurally, chrysocolla has been described as a colloidal assemblage or hydrogel of silica, water, and various copper oxide or hydroxide minerals, and has a wide range of compositional substitutions including $\mathrm{Cu}, \mathrm{Al}, \mathrm{Mg}$, $\mathrm{Ca}, \mathrm{Fe}$ and $\mathrm{H}$, along with varying degrees of hydration [1].

As part of a larger study on the comparative leaching behaviour of chrysocolla, a set of eight specimens from different sources were analysed by hyperspectral x-ray mapping in a JEOL JXA-8500F field emission gun electron probe microanalyser (FEG-EPMA) in order to measure the elemental composition of the chrysocolla and the variability therein. In addition to the need for trace element sensitivity $(<$ $1000 \mathrm{ppm}$ ), the fine texture of the chrysocolla required spatial resolution of better than $5 \mu \mathrm{m}$. Unfortunately, chrysocolla decomposes readily under electron beam irradiation due to the high proportion of water and $\mathrm{OH}^{-}$anions, which precludes conventional trace point analysis by EPMA. It was recently demonstrated that quantification based on spectra integrated from clustered energy dispersive $\mathrm{x}$-ray spectrometry (EDS) hyperspectral maps can result in $<10 \mathrm{ppm}$ minimum detection limits without observable beam damage on sensitive materials such as quartz [2]. These methods were further extended in this study, where a combination of clustering, image analysis, and standards-based EDS quantification was used to determine the trace element content of each grain of chrysocolla within the mapped areas. The analysis conditions were a $12 \mathrm{kV}$ probe with a beam current of $60 \mathrm{nA}$, focussed to a $2 \mu \mathrm{m}$ diameter spot with matching $2 \mu \mathrm{m}$ pixel steps in stage-scanned grid of $1600 \times 1600$ pixels $(3.2 \mathrm{~mm} \times 3.2 \mathrm{~mm})$, with a dwell time of $25 \mathrm{~ms}$ per pixel.

A typical phase map of a chrysocolla specimen is shown in figure 1a, showing chrysocolla (21.5\% modal area) intergrown with a significant abundance of other $\mathrm{Cu}$-bearing species such as malachite $\left(\mathrm{Cu}_{2}\left(\mathrm{CO}_{3}\right)(\mathrm{OH})_{2}, 49.7 \%\right.$ modal area), brochantite $\left(\mathrm{Cu}_{4}\left(\mathrm{SO}_{4}\right)(\mathrm{OH})_{6}, 2.8 \%\right)$, chalcocite $\left(\mathrm{Cu}_{2} \mathrm{~S}, 4.4 \%\right)$, and atacamite $\left(\mathrm{Cu}_{2} \mathrm{Cl}(\mathrm{OH})_{3}, 2.6 \%\right)$, as well as gangue phases such as quartz $\left(\mathrm{SiO}_{2}, 7.3 \%\right)$, dolomite $\left(\mathrm{CaMg}\left(\mathrm{CO}_{3}\right)_{2}, 5.4 \%\right)$, kaolinite $\left(\mathrm{Al}_{2} \mathrm{Si}_{2} \mathrm{O}_{5}(\mathrm{OH})_{4}, 1.9 \%\right)$, and others. Grain-detection using in-house image analysis software was used to calculate a binary 'mask' map of the chrysocolla phase within each composite grain (Fig 1.b), which was then used to extract the integrated spectra of the chrysocolla from the hyperspectral EDS map datasets on a grain-by-grain basis. Because the trace elements of interest in chrysocolla are also present as major elements in neighbouring phases (e.g. $\mathrm{Al}$ in kaolinite, $\mathrm{Ca}$ and $\mathrm{Mg}$ in dolomite), the chrysocolla grain masks were digitally 'eroded' prior to spectrum extraction to excise edge pixels within a $4 \mu \mathrm{m}$ ( 2 pixel) distance of any non-chrysocolla pixels, which could otherwise have spuriously enhanced the apparent trace element signal in the chrysocolla.

The chrysocolla spectra from a total of 618 grains in the eight specimens were extracted using a minimum grain area threshold of $400 \mathrm{um}^{2}$, corresponding to a minimum total real-time dwell of 2.5 seconds per 
analysis. In total, 925k pixels of chrysocolla were included in the analysis, corresponding to an area of $3.7 \mathrm{~mm}^{2}$; approximately $4.5 \%$ of the total mapped area of $81.9 \mathrm{~mm}^{2}$. The integrated peak intensities of the characteristic x-ray lines from the grain spectra and from the spectra of appropriate matrix-matched mineral standards were extracted using least-squares Gaussian peak deconvolution, and matrix corrected using the exponential Pouchou and Pichoir (XPP) algorithm as implemented in the StrataGEM library [3].

The results of the grain-by-grain quantitative analyses showed the distributions of trace element concentrations of the chrysocolla within the different specimens were resolvable (figure 2). The median differential detection limits for the grain analyses of $\mathrm{Mg}, \mathrm{Al}$ and $\mathrm{Ca}$ were $\pm 990 \mathrm{ppm}, \pm 155 \mathrm{ppm}$ and $\pm 330 \mathrm{ppm}(\mathrm{w} / \mathrm{w})$, respectively, calculated at the $3 \sigma(99.7 \%$ confidence $)$ interval. The best single-grain detection limits achieved were $\pm 260 \mathrm{ppm} \mathrm{Mg}, \pm 40 \mathrm{ppm} \mathrm{Al}$ and $\pm 84 \mathrm{ppm} \mathrm{Ca}$. The relatively poor excitation efficiency of $\mathrm{Cu} \mathrm{K \alpha}$ at $12 \mathrm{kV}$ resulted in a median differential detection limit for $\mathrm{Cu}$ in chrysocolla that was worse than for the lighter elements, at $\pm 0.65 \mathrm{wt} \%$. However, these detection limits were sufficient to observe that the chrysocolla of two specimens (10015 and 10017) had the lowest trace element substitution of the analysed set, with median concentrations of 760-910ppm Mg, 170-190ppm Al, and 720-1,570ppm Ca. Conversely, the chrysocolla in three specimens (10010, 10014, and 10016) showed considerable substitution of $\mathrm{Al}$ for $\mathrm{Cu}$ (Fig. 2b), with the median Al content of the chrysocolla in sample 10016 at $1.15 \mathrm{wt} \%$, and the highest single grain reporting $1.27 \pm 0.05 \mathrm{wt} \% \mathrm{Al}$. These three specimens also exhibited a relatively high degree of $\mathrm{Mg}$ and $\mathrm{Ca}$ incorporation, with single-grain analyses of up to $1.77 \pm 0.12 \mathrm{wt} \%$ $\mathrm{Mg}$ and $0.95 \pm 0.11 \mathrm{wt} \% \mathrm{Ca}$.

This investigation demonstrates the significant capacity for quantitative analysis of hyperspectral map data to reveal trace element distributions in circumstances that would severely challenge conventional point trace analysis, such as with beam sensitive phases that are finely textured within multi-phase grains.
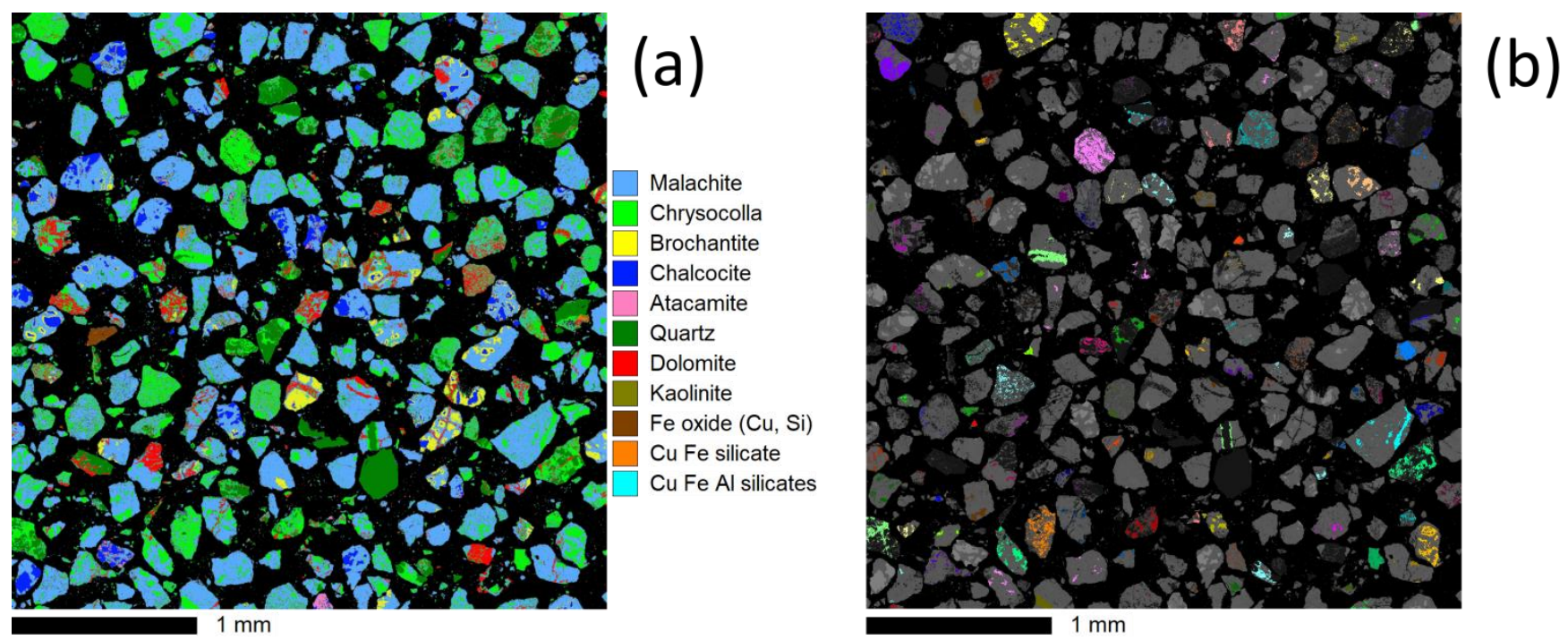

Figure 1. (a) clustered phase map of specimen 10011, and (b) corresponding chrysocolla phase mask, with arbitrary colours assigned to highlight the chrysocolla within each composite grain aggregate, which were analysed separately. 

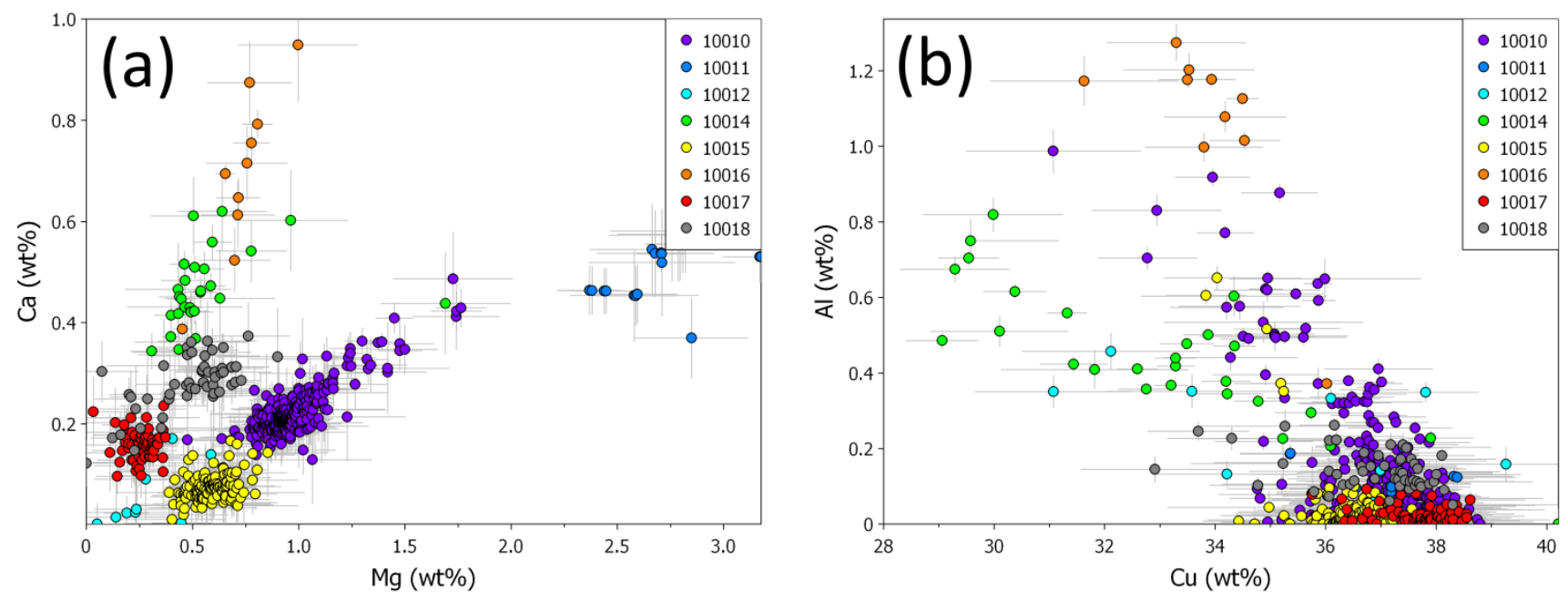

Figure 2. (a) Scatter plot of Ca versus $\mathrm{Mg}$ for chrysocolla in all analysed grains (618 total), showing distinct compositional clusters for each specimen. Differential detection limits were calculated individually for each grain analysis and are plotted as error bars at the $3 \sigma$ interval. (b) Scatter plot of Al versus $\mathrm{Cu}$, showing $\mathrm{Al}-\mathrm{Cu}$ substitution occurring at comparatively low (samples 10015, 10017) and high rates $(10014,10010$ and 10016).

\section{References}

[1] Crane, M.J., Sharpe, J.L. and Williams, P.A. (2001). Formation of chrysocolla and secondary copper phosphates in the highly weathered supergene zones of some Australian deposits. Records-Australian Museum, 53(1), pp.49-56.

[2] Torpy, A., Wilson, N., MacRae, C., Pownceby, M., Biswas, P., Rahman, M., \& Zaman, M. (2020). Deciphering the Complex Mineralogy of River Sand Deposits through Clustering and Quantification of Hyperspectral X-Ray Maps. Microscopy and Microanalysis, 26(4), 768-792. doi:10.1017/S143192762000135X

[3] http://www.samx.com/microanalysis/products/stratagem_us.html 